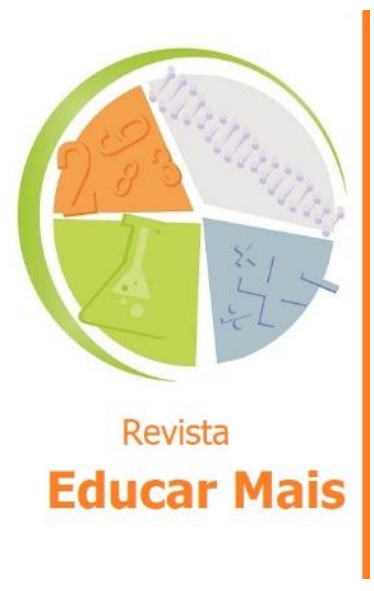

\section{Educação Emocional: intervenção em uma escola de Ensino Médio em Pernambuco}

\author{
Emotional Education: intervention in a High School in Pernambuco \\ Educación Emocional: intervención en una Escuela Secundaria de \\ Pernambuco
}

Mariana Marques Arantes ${ }^{1}$; Aurino Lima Ferreira ${ }^{1}$; Eugênia Paula Cordeiro²; Carla de Paula Campos ${ }^{1}$

\title{
RESUMO
}

Este artigo apresenta os resultados de uma pesquisa voltada para o desenvolvimento das emoções na educação, com o envolvimento de duas pesquisadoras, quatro professoras copesquisadoras e 139 estudantes do primeiro ano do ensino médio de uma escola estadual de referência da Região Metropolitana do Recife, Pernambuco. Adotamos uma abordagem qualitativa, exploratória e propositiva por meio de uma pesquisa-ação. As análises foram realizadas de forma interpretativa com o suporte do software Iramuteq. A intervenção indicou a importância de: manter uma escuta sensível quanto às vivências dos participantes; perceber os docentes como copesquisadores, entendendo que os fundamentos teóricos integrados à experiência prática deles geram conhecimento e que se devem respeitar as singularidades de cada docente. $O$ desenvolvimento de habilidades como autoconhecimento e autogestão estimulou a compreensão mútua, promovendo a empatia entre os participantes (docentes-discentes e discentes entre si), e contribuiu para a regulação da impulsividade, proporcionando relações mais humanizadas no ambiente escolar em foco e na vida em sociedade.

Palavras-chave: Educação emocional; Habilidades socioemocionais; Formação humana; Inteligência emocional.

\begin{abstract}
This article presents the results of a research focused on the development of emotions in education, with the involvement of two researchers, four co-research teachers and 139 first-year high school students from a state reference school in the Metropolitan Region of Recife, Pernambuco. We adopt a qualitative, exploratory and purposeful approach through action research. The analyzes were performed interpretively with the support of the Iramuteq software. The intervention indicated the importance of: maintaining a sensitive listening to the participants' experiences; perceive teachers as co-researchers, understanding that the theoretical foundations integrated into their practical experience generate knowledge and that the singularities of each teacher must be respected. The development of skills such as self-knowledge and self-management stimulated mutual understanding, promoting empathy among participants (teacher-students and students among themselves), and contributed to the regulation of impulsivity, providing more humanized relationships in the school environment in focus and in life in society.
\end{abstract}

Keywords: Emotional education; Socio-emotional skills; Human formation; Emotional intelligence.

\section{RESUMEN}

Este artículo presenta los resultados de una investigación centrada en el desarrollo de las emociones en la educación, con la participación de dos investigadores, cuatro co-profesores de investigación y 139 estudiantes de primer año de secundaria de una escuela de referencia estatal en la Región Metropolitana de Recife,

\footnotetext{
${ }^{1}$ UFPE - Universidade Federal de Pernambuco, Recife/PE - Brasil.

${ }^{2}$ IFPE - Instituto Federal de Pernambuco, Recife/PE - Brasil.
} 
Pernambuco. Adoptamos un enfoque cualitativo, exploratorio y con propósito a través de la investigaciónacción. Los análisis se realizaron de forma interpretativa con el apoyo del software Iramuteq. La intervención indicó la importancia de: mantener una escucha sensible de las experiencias de los participantes; percibir a los docentes como co-investigadores, entendiendo que los fundamentos teóricos integrados en su experiencia práctica generan conocimientos y que se deben respetar las singularidades de cada docente. El desarrollo de habilidades como el autoconocimiento y la autogestión estimuló el entendimiento mutuo, promoviendo la empatía entre los participantes (docente-alumnos y alumnos entre ellos), y contribuyó a la regulación de la impulsividad, brindando relaciones más humanizadas en el entorno escolar en el enfoque y en la vida en sociedad.

Palabras clave: Educación emocional; Habilidades socioemocionales; Formación humana; Inteligencia emocional.

\section{INTRODUÇÃo}

Este artigo resulta de uma tese de doutorado de abordagem qualitativa, exploratória e propositiva que empregou uma pesquisa-ação, realizada em uma escola estadual de referência da Região Metropolitana do Recife, Pernambuco. Esse procedimento metodológico foi aplicado pelas pesquisadoras com as docentes em uma ação interventivo-formativa continuada e entre as docentes e os estudantes no processo de implementação do Projeto Conecte-se: Sentindo, Pensando e Agindo em questão. Trata-se de um projeto de extensão acadêmica de educação socioemocional numa perspectiva de integralidade e multidimensionalidade da formação do ser humano - física, sensorial, emocional, mental, espiritual (RÖHR, 2010; 2013). Ele busca contribuir com os debates acerca dos programas nacionais e estaduais de Educação Integral (SILVA; SILVA, 2016; BRASIL, 2015; CAVALIERE, 2014; MOLL et al., 2012), principalmente na crítica a adesão de visões restritivas da integralidade a sua temporalidade, pois como indica Arroyo (2012, p. 33): "[...] uma forma de perder seu significado político será limitar-nos a oferecer mais tempo da mesma escola, ou mais um turno turno extra - ou mais educação do mesmo tipo de educação".

Teoricamente, o Projeto Conecte-se: Sentindo, Pensando e Agindo compreende a formação humana enquanto um processo educativo que implica a prática autorreflexiva por parte de educadores e educandos no sentido de estimular a conscientização de processos que visam ao benefício do coletivo escolar e não apenas de um indivíduo ou grupo.

De acordo com tal entendimento, o processo esclarecido da formação humana, ou humanização, necessita reconhecer aquilo que nas dimensões corpórea, emocional e mental se apresenta como tendências compulsivas, impulsos regressivos ou hábitos destrutivos. [...] Em nossas dimensões corpórea, emocional e mental, precisamos todos nós aprender a enfrentar dificuldades, a tolerar a frustração, a desenvolver a paciência, a nos abrirmos às relações sábias e construtivas, a empreender iniciativas favoráveis a nós e aos outros (POLICARPO JR., 2011, p. 97)

Nessa perspectiva, considera-se que o campo de estudo e pesquisa em Habilidades Socioemocionais e Valores na Educação (HSEV) contribui para um processo mais amplo de humanização do ser, assim como busca trazer contribuições para ampliar o debate acerca das políticas públicas voltadas a educação integral.

Arantes (2019) realizou uma revisão da literatura no campo acadêmico brasileiro a partir dos descritores "educação emocional", "educação socioemocional", "habilidades socioemocionais" e "inteligência emocional", considerando as Ciências Humanas da Educação e da Psicologia e buscando publicações científicas nos bancos de dados, repositórios e acervos da Associação Nacional de Pós- 
Graduação e Pesquisa em Educação (ANPED), da Biblioteca Digital de Dissertações e Teses (BDTD), da Biblioteca Virtual em Saúde (BVS), da Coordenação de Aperfeiçoamento de Pessoal de Nível Superior (CAPES) e do Instituto Nacional de Estudos e Pesquisas Educacionais Anísio Teixeira (INEP). Os quatro termos descritores foram selecionados a partir da literatura referenciada para demarcar 0 campo conceitual de cada um deles, assim como para nortear teoricamente as ações do projeto.

a) Educação emocional é a possibilidade de adquirir conhecimento por palavras e ações. Reconhecer o poder das emoções no que concerne à capacidade de nos revelar a nós mesmos faz com que sejamos pessoas melhores, vivendo uma vida mais plena e consciente (CASASSUS, 2009).

b) Educação socioemocional é o processo educativo contínuo, permanente e preventivo articulado com o objetivo de desenvolver a inteligência emocional e/ou as competências emocionais ou socioemocionais que capacitem o indivíduo para lidar melhor com os desafios do cotidiano (BISQUERRA, 2000; PÉREZ-GONZALEZ; GARRIDO, 2011).

c) Habilidades socioemocionais são o conjunto de competências afetivas, cognitivas e comportamentais que possibilita mais coerência na forma de pensar, sentir e agir (DURLAK et al., 2015).

d) Inteligência emocional é uma expressão criada pelos pesquisadores americanos Peter Salovey e John D. Mayer e popularizada por Daniel Goleman em meados dos anos 90 do século XX. Referese a um subconjunto da inteligência social que envolve a capacidade de monitorar as próprias emoções e sentimentos, bem como as dos outros, para discriminar entre eles e usar essa informação para guiar o pensamento e as ações (SALOVEY; MAYER, 1990; GOLEMAN, 2007).

Foram mapeados 156 trabalhos, sendo 101 artigos, 34 dissertações, 18 teses, um livro, uma entrevista e um boletim técnico. Entre os anos de 1993 e 2000 tiveram um total de 9 trabalhos, enquanto de 2001 a 2010 este número vai para 58, chegando a um total de 89 produções no período entre 2011 e 2018. No entender de Arantes (2019), o crescimento da investigação científica sobre o manejo das emoções no Brasil a partir do ano 2000 deve-se a dois aspectos: o primeiro é a popularização da temática nos Estados Unidos, estimulada por estudos que contribuíram para a compreensão da existência de múltiplas formas de inteligência (GARDNER, 2005) e da própria inteligência emocional (MAYER; SALOVEY, 1995; MAYER; SALOVEY; CARUSO, 2004), assim como pelo sucesso do livro do jornalista e pesquisador Daniel Goleman, publicado no território brasileiro como Inteligência emocional - por que ela pode ser mais importante que o QI, que se tornou um best-seller mundial pouco depois do lançamento, em 1995. O segundo aspecto é a necessidade premente de lidar com os problemas de relacionamento intra e interpessoais dentro das escolas. É inegável que o clima emocional deteriorado influencia negativamente o processo de ensino-aprendizagem (UNESCO, 2001; OCDE, 2011). Também há evidências que relacionam, de um lado, a ausência de conhecimento sobre o manejo das emoções a problemas de saúde dos docentes como o sofrimento psíquico e o esgotamento físico e mental (MAZON; CARLOTTO; CÂMARA, 2003; NEVES; SILVA, 2006; MARIANO; MUNIZ, 2006; GOMES; BRITO, 2006; GOMES et al., 2010; POCINHO; PERESTRELO, 2011; COSTA et al., 2013 e SILVA et al., 2015); a conexão entre estresse e rendimento escolar (GOMES; BRITO, 2006; PASIN; PAI; LANNES, 2012) e a possibilidade de uso da educação emocional como favorecedora de processos adaptativos a modelos neoliberais (SILVA, 2018).

O Projeto Conecte-se: Sentindo, Pensando e Agindo foi elaborado com base em estudos e pesquisas denominados de Social and Emotional Learning (SEL), traduzidos como "Aprendizado 
Socioemocional", expressão cunhada em 1994 por um grupo de pesquisadores e educadores reunidos no Fetzer Institute, de Michigan, EUA, com o objetivo de debater estratégias para o desenvolvimento de competências socioemocionais, acadêmicas, de saúde e de cidadania em crianças e adolescentes com vistas a levar para a educação meios de lidar com problemas de saúde mental e comportamental (WEISSBERG et al., 2015). Assim como as contribuições da primeira organização de estudos e pesquisas científicas em SEL, a Collaborative for Academic, Social, and Emotional Learning (CASEL), tem entre seus principais objetivos identificar as melhores práticas educacionais para maximizar 0 desenvolvimento socioemocional saudável em crianças, assim como o desempenho acadêmico e o comportamento ético e cidadão.

Cinco são os domínios de competências elencados pela CASEL (WEISSBERG et al., 2015) adotados no Projeto Conecte-se: 1 . Autoconhecimento, apresentado como uma capacidade de compreender as próprias emoções, assim como seus objetivos pessoais e valores, reconhecendo as próprias qualidades e limitações, e como pensamentos, sentimentos e ações estão interconectados; 2. Autogestão, que é a capacidade de regular emoções e comportamentos, gerenciar o estresse e regular impulsos; 3. Consciência social, tomada como uma habilidade de assumir a perspectiva dos que têm um contexto histórico ou cultural diferente, como também de empatizar e sentir compaixão; 4. Habilidades relacionais, definidas como o estabelecimento e a manutenção de relacionamentos saudáveis e gratificantes para o exercício de comunicação clara, escuta ativa, cooperação, negociação construtiva dos conflitos; 5 . Tomada de decisão responsável, definida como uma competência que requer conhecimento, habilidades e atitudes necessárias para fazer escolhas considerando padrões éticos, a preocupação com a segurança, a avaliação realista de consequências de várias ações, bem como a saúde e o bem-estar próprios e dos demais.

Produções nesse campo de pesquisa vêm se desenvolvendo ao redor do mundo. Podem ser encontradas em publicações ${ }^{3}$ da Fundación Botín (2008, 2011, 2013, 2015), a qual tem sede em Santander, Espanha, desde 2007 e analisa iniciativas de programas que envolvem educação social e emocional. Como iniciativa da própria Fundación, destacamos seu programa intitulado Educación Responsable, no qual se realiza

un proceso global (investigación, creación, implementación, apoyo y evaluación) para ofrecer recursos y técnicas educativas que facilitan y fomentan el desarrollo emocional, cognitivo y social de niños y jóvenes, ayudándoles a ser autónomos, competentes, responsables y solidarios. (FUNDACIÓN MARCELINO BOTÍN, 2008, p. 11)

No Brasil, as pesquisas na área de educação emocional ainda são pontuais e incipientes no setor público (Arantes, 2019). Nesse sentido, procuramos neste artigo apresentar os resultados de uma pesquisa realizada entre os anos de 2015-2016, voltada para a educação emocional, especialmente para o desenvolvimento do autoconhecimento e da autogestão, com o envolvimento de duas pesquisadoras, quatro professoras copesquisadoras e 139 estudantes do primeiro ano do ensino médio de uma escola estadual de referência da Região Metropolitana do Recife, Pernambuco. Mais especificamente, situamos os resultados oriundos das conversas gravadas durante os grupos focais realizados com os estudantes tendo em vista os critérios delimitativos deste artigo.

${ }^{3}$ FUNDACIÓN BOTÍN. Educación Emocional y Social. Área de Educación de Fundación Botín. 2015. Disponível em: https://www.fundacionbotin.org/educacion-contenidos/educacion-emocional-y-social-analisisinternacional.html. Acesso em: 15 nov. 2018. 


\section{PERCURSO METODOLÓGICO}

Fez-se uso de uma abordagem qualitativa, exploratória e propositiva, por meio de pesquisa-ação (BARBIER, 2007), em uma escola estadual de referência da Região Metropolitana do Recife. Esse procedimento metodológico foi aplicado pelas pesquisadoras com as docentes em uma ação interventivo-formativa continuada e entre as docentes e os estudantes ao longo do processo de implementação do Projeto em questão. Os achados foram analisados de forma interpretativa com o suporte do software Iramuteq ${ }^{4}$. A seguir, faz-se uma contextualização do caminho percorrido, inicialmente com o processo formativo das professoras ao longo de 2015 até chegar aos grupos focais empreendidos com os estudantes ao final do primeiro ano de implementação do projeto, em 2016, para então evidenciar os resultados obtidos com eles.

A orientação teórica considerada neste artigo está fundamentalmente ligada à mobilização de pessoas que constroem pontes entre o conhecimento filosófico sobre a formação humana e a educação, integrada à prática pedagógica de professoras que atuam no ensino médio.

A pesquisa-ação obriga o pesquisador de implicar-se. Ele percebe como está implicado pela estrutura social na qual ele está inserido e pelo jogo de desejos e de interesses de outros. Ele também implica os outros por meio do seu olhar e de sua ação singular no mundo. Ele compreende, então, que as ciências humanas são, essencialmente, ciências de interações entre sujeito e objeto de pesquisa. (BARBIER, 2007, p. 14)

Partindo desse entendimento, considera-se o aprendizado de tornar-se mais consciente da dinâmica do sentir, do pensar e do agir, por parte de todos os envolvidos na pesquisa, como de extrema importância para a formação humana.

Cunha (2017, p. 44) possibilita admitir a complexidade das pesquisas educacionais desse tipo ao colocar que o estudo da formação humana requer uma perspectiva multiparadigmática, "[...] fundamentada em uma rede de pressupostos ontológicos, epistemológicos e metodológicos que definem a visão de mundo e da natureza do pesquisador".

Uma vez que se tratou de um projeto de extensão, foi estabelecido um convênio institucional e todos os sujeitos envolvidos tiveram entrada espontânea e devidamente oficializada na pesquisa mediante a assinatura do termo de consentimento livre e esclarecido (TCLE) pelos maiores de 18 anos e pelos responsáveis dos menores de idade. $O$ termo de assentimento livre e esclarecido (TALE) foi utilizado no caso dos discentes menores de idade.

\subsection{Os sujeitos participantes}

Foram sujeitos da pesquisa em tela 139 alunos com idades entre 14 e 16 anos, de quatro turmas (10 $A, 1^{\circ} \mathrm{B}, 1^{\circ} \mathrm{C} \mathrm{e} 1^{\circ} \mathrm{D}$ ) de primeiro ano, ingressantes em 2016 em uma escola de referência de ensino médio em Pernambuco, além de:

- Professoras: quatro professoras, que tratamos por Docentes A, B, C e D nas informações do perfil sociodemográfico preenchido por elas em março de 2016. Ressalva-se que mais adiante, nos resultados, para eliminar qualquer possibilidade de identificação delas, foi modificada a forma de referenciamento e passou-se a utilizar a codificação da organização do software de análise que identifica somente a gravação e não o autor do discurso. À época, as professoras tinham entre 34

\footnotetext{
${ }^{4}$ Interface R para análises multidimensionais de textos e questionários
} 
e 50 anos de idade e 14 e 30 anos de docência no total, sendo de 3 a 8 anos no ensino médio. Todas trabalhavam dois turnos com carga total de 200 horas-aula e lecionavam disciplinas para as turmas do primeiro ano. Três já tinham exercido cargos diferentes no ensino além da docência, sendo que duas delas já tinham tido experiência como gestoras.

- Pesquisadoras: duas pesquisadoras, sendo uma a líder do grupo, doutora em Educação, que vem pesquisando a formação humana na perspectiva da integralidade desde 2008 em aulas de relações interpessoais em cursos tecnológicos. A outra, à época, era membro do mesmo grupo de pesquisa, doutoranda em Educação da UFPE e bolsista vinculada à Fundação de Amparo a Ciência e Tecnologia do Estado de Pernambuco (FACEPE), mestre em Educação.

\subsection{Giro 1: roteiro interventivo-formativo voltado para a formação humana}

Tomou-se como fio condutor o processo de pesquisa-ação formativo-participativo, estimulante de reflexões com as docentes a respeito de fundamentos teórico-filosóficos da educação em torno das múltiplas dimensões do ser (física, sensorial, emocional, mental, espiritual) (RÖHR, 2010, 2013) e da importância de um olhar integral do humano. Além de possibilitarem uma discussão sem que houvesse a necessidade de leituras prévias, apenas a experiência humana, essas reflexões forneciam insumos para que estimulássemos a prática da auto-observação do sentir, do pensar e do agir. A tomada de consciência da dinâmica interna das dimensões favorece o autoconhecimento, principalmente quando as ações estão contaminadas por motivações impulsivas. Para estimular essa percepção, introduziu-se um momento de aquietamento antes de cada encontro ao mesmo tempo que foi escolhido um tema para orientar as discussões com cada grupo de docentes. Os encontros eram quinzenais, conforme mostra o Quadro 1.

Quadro 1 - Temas dos encontros do giro 1 - 2015

\begin{tabular}{|c|l|l|}
\hline Encontro & \multicolumn{1}{|c|}{ Data } & \multicolumn{1}{c|}{ Tema } \\
\hline 1 & 11 de março & Influência do entorno nas nossas escolhas e ações \\
\hline 2 & 25 de março & As múltiplas dimensões do ser - a integralidade \\
\hline 3 & 08 de abril & As múltiplas dimensões do ser: pensar, sentir, agir \\
\hline 4 & 22 de abril & $\begin{array}{l}\text { Dimensão sensorial - corporalidade físico-biológica, sensações físicas, calor-frio, } \\
\text { dor-prazer físico, doce-amargo, enfim, a percepção que temos através dos } \\
\text { nossos cinco sentidos. }\end{array}$ \\
\hline 5 & 06 de maio & $\begin{array}{l}\text { Dimensão emocional - aspectos biológicos, psicológicos, social e cultural das } \\
\text { emoções. }\end{array}$ \\
\hline 6 & 20 de maio & $\begin{array}{l}\text { Dimensão mental - aspectos cognitivos desde a lógica matemática até a } \\
\text { capacidade de reflexão - de questionar todas as coisas, inclusive a si mesmo -, } \\
\text { a recordação e a memória, a imaginação e a fantasia, a compreensão e a criação } \\
\text { de ideias e, finalmente a nossa intuição, em que sabemos, sem poder justificar, } \\
\text { em última instância, por que sabemos. }\end{array}$ \\
\hline 7 & 3 de junho & Dimensão espiritual - os valores éticos e o sentido da vida. \\
\hline 8 & 17 de junho & Fechamento 1 - reflexão acerca dos encontros anteriores. \\
\hline 9 & 8 de julho & Fechamento 2 - reflexões com base em exemplos vividos em sala de aula. \\
\hline & & \multicolumn{2}{|c|}{ Fonte: Elabacaa própia. } \\
\hline
\end{tabular}
Fonte: Elaboração própria.

Em seguida, sempre numa roda de conversa, as professoras passavam a relatar experiências e percepções sobre os relacionamentos interpessoais na escola e no período de intervalo entre os encontros. O Projeto proporcionava um momento de "resolução de conflitos" entre os próprios 
integrantes do grupo, tendo em vista que no dia a dia da rotina escolar eles não tinham tempo de lidar com esses entraves.

Observou-se que participar da iniciativa para elas estava acima dos seus impasses relacionais. Dessa forma, o Projeto propiciou muitos momentos de conversa franca que dirimiam aos poucos conflitos interpessoais entre as participantes. As pesquisadoras relatam que aprenderam que um Projeto dessa natureza requer paciência e escuta ativa para que os sujeitos pratiquem a compaixão e a pacificação em grupo. Exemplificam que, muitas vezes, o roteiro era alterado em função dessa necessidade e assim foram aprendendo a ser flexíveis, permitindo que a necessidade do grupo prevalecesse. Acontecimentos similares passaram a constituir a base do processo formativo, promovendo intensos e profícuos momentos de amadurecimento intra e interpessoal para os participantes.

Os encontros relatados no Projeto mostram uma troca de vivências no ambiente escolar do qual as pesquisadoras estavam se aproximando que favoreceu o exercício das competências socioemocionais, deixando nítido que o compartilhamento de experiências e suas diferentes percepções permitia saber mais sobre as participantes, sobre si mesmas e sobre o clima emocional como um todo.

\subsection{Giro 2 - roteiro interventivo-formativo voltado para as HSEV}

O Quadro 2 mostra os temas norteadores das discussões em grupo de cada encontro a partir do segundo semestre de 2015.

Quadro 2 - Encontros do segundo semestre de 2015 ao início de 2016

\begin{tabular}{|c|l|l|}
\hline Encontros & \multicolumn{1}{|c|}{ Data } & \multicolumn{1}{c|}{ Tema } \\
\hline 1 & $02 / 09 / 2015$ & O ser emocional \\
\hline 2 & $16 / 09 / 2015$ & Autoconsciência \\
\hline 3 & $30 / 09 / 2015$ & Autogestão \\
\hline 4 & $14 / 10 / 2015$ & Consciência social \\
\hline 5 & $28 / 10 / 2015$ & Habilidades relacionais \\
\hline 6 & $11 / 11 / 2015$ & Tomada de decisão responsável \\
\hline 7 & $25 / 11 / 2015$ & Avaliação de 2015 \\
\hline 8 & $11 / 12 / 2015$ & Encerramento de 2015 e início do planejamento 2016 \\
\hline 9 a 14 & Fev./mar. 2016 & Planejamento para iniciar o Projeto com os estudantes \\
\hline
\end{tabular}

Fonte: Elaboração própria.

O giro terminou em abril de 2016, com o início da implementação do Projeto junto aos alunos. Nesse período, foi estruturado um cronograma (Quadro 3) de 16 encontros com os estudantes para compartilhar o conhecimento construído até aquele momento. Elegeu-se iniciar com as emoções básicas - raiva, medo, tristeza e alegria -, tendo em vista que seus efeitos são bem familiares a todos.

Quadro 3 - Planejamento inicial do Projeto para 2016

\begin{tabular}{|c|c|}
\hline Encontro & Atividade \\
\hline 1 & Aplicação de escala \\
\hline 2 & Apresentação do Projeto \\
\hline 3 & Noções de multidimensionalidade \\
\hline
\end{tabular}




\begin{tabular}{|c|c|}
\hline $4-5-6$ & Raiva \\
\hline $7-8-9$ & Medo \\
\hline $10-11-12$ & Tristeza \\
\hline $13-14-15$ & Alegria \\
\hline 16 & Avaliação final \\
\hline
\end{tabular}

Fonte: Projeto (2016).

Os dois primeiros encontros foram direcionados para a aplicação de uma escala organizada pelas pesquisadoras no intuito de mapear as emoções que os participantes desejavam mais conhecer, assim como levantar o clima emocional vivido na sala de aula e na escola e a solicitação de assinatura do TCLE por pais e responsáveis. No encontro 3, estava previsto o planejamento de dinâmicas que pudessem fornecer aos estudantes noções da teoria da multidimensionalidade.

Do quarto ao décimo quinto encontros, o grupo escolheu trabalhar o manejo das emoções básicas raiva, medo, tristeza e alegria - com os estudantes. Apesar da observação participante, predominantemente, ter se dado ao longo de todo o processo por parte das docentes, ao final desse ciclo planejou-se a realização de grupos focais para fins avaliativos e de apreensão do conhecimento compartilhado entre os estudantes. Sem a necessidade de muitas teorizações sobre habilidades socioemocionais, a ideia era motivá-los, a partir da própria experiência de vida e de conexão com o ambiente, a falar e refletir sobre as suas formas de sentir, pensar e agir quando tomados pelas emoções básicas.

Produzimos com as docentes tutoriais com sugestões de atividades para serem desenvolvidas em sala de aula e fichas para estudo e reflexão, de apoio para os estudantes, sobre raiva, medo, tristeza e alegria. Ressalta-se que os tutoriais serviam apenas de roteiro básico para as docentes, passíveis de serem recriados ou deixados de lado de acordo com a necessidade de cada uma. Como o ambiente escolar é muito dinâmico e os acontecimentos aguçam a criatividade, as docentes puderam adaptar as atividades à realidade de cada momento.

O planejamento foi concluído e o Projeto teve seu propósito ampliado com a participação direta dos discentes. Assim, iniciou-se o terceiro giro da pesquisa-ação.

\subsection{Giro 3 - Formação docente continuada e início da implementação do Projeto com os estudantes}

O giro 3 aconteceu de 18 de abril a 9 de dezembro de 2016. O Projeto foi aplicado em sala de aula pelas docentes com a devida autorização da direção da escola e dos responsáveis pelos estudantes menores de idade. O período abarcou dois tipos simultâneos de atividades:

- Entre pesquisadoras e docentes: no mesmo formato do giro 2, encontros quinzenais para a avaliação das atividades aplicadas em sala de aula por cada docente e planejamento das próximas. A partir desse aprendizado mútuo, as atividades iam sendo construídas com a colaboração de pesquisadoras e docentes.

- Entre docentes e alunos: aplicação em sala de aula das atividades. Não havia calendário rígido e a combinação de cada docente seguiu seu próprio andamento para não atrapalhar o conteúdo formal das disciplinas, além de preservar a forma de ver cada turma sob o olhar da professora. No fim do ano letivo de 2016, foram 12 encontros de atividades em cada turma participante, girando em 
torno dos seguintes temas centrais: a conexão entre sentir, pensar e agir a partir das quatro emoções básicas (tristeza, raiva, medo e alegria).

As professoras tiveram bastante criatividade individual e autonomia. Essa foi uma marca do giro 3, lembrando que a integração entre o conhecimento acadêmico das pesquisadoras e o conhecimento prático da sala de aula produziram um novo conhecimento do fazer pedagógico voltado para o desenvolvimento das emoções. Uma vez que não havia espaço oficial na grade curricular para o Projeto, era necessário que as professoras adaptassem prazos e estratégias didáticas, bem como que lidassem com imprevistos como reuniões marcadas subitamente pela direção, entre outros. No Projeto, percebe-se que foram necessárias muita criatividade e habilidade de negociação para que fosse possível atender às demandas formais da escola e da intervenção formativa, evidenciando que, se não fosse o comprometimento do grupo de docentes com a humanização do ser, o trabalho seria inviabilizado.

Uma das pesquisadoras-autoras ocupou o papel de observadora participante em alguns encontros dessa fase de implementação. Ao longo do processo, ratificou-se a importância de oferecer às educadoras fundamentos teórico-filosóficos como base para dar vazão à sua autonomia sem que fosse necessário um modelo rígido a ser seguido.

Percebeu-se in loco o comportamento de cada professora: a afetação dos seus estados emocionais na maneira de planejar e de falar com os estudantes, e sua reação à nossa presença na sala. Uma delas manejou tempo e atividade, já que essa é uma característica sua. Outra ficou nitidamente nervosa, preocupada em dar o máximo de tempo possível às conversas em sala, achando que o programado por ela não seria suficiente. Relatou, inclusive, que sentiu, de algum modo, como se estivesse sendo avaliada, "como uma estudante em época de prova". Acabou assumindo que se sentiria mais à vontade sem a presença das pesquisadoras. Isso posto, as pesquisadoras respeitaram os sentimentos de cada docente.

Quinzenalmente, continuaram a ser realizados encontros para direcionamentos e acordos mútuos em meio à elaboração das atividades. O Projeto relata que o clima era de confiança, cooperação e construção coletiva entre as pesquisadoras e as professoras, o que contribuiu para que as docentes lutassem pela continuidade do trabalho em dado momento em 2016 quando motivos externos ameaçaram sua permanência.

\subsection{Metodologia analítica}

Os achados que serão apresentados a seguir são fruto de análises interpretativas, lexicográficas e de similitude, oriundas apenas das conversas gravadas durante os grupos focais realizados com os estudantes, tendo em vista os critérios delimitativos deste artigo. Lexicometria é um conjunto de métodos que permite reorganizar a configuração de uma sequência textual e realizar análises estatísticas relativas ao vocabulário de corpora textuais (CAMARGO; JUSTO, 2013, p. 514).

Como ferramenta de apoio para o processamento dos dados, utilizamos o software Iramuteq ${ }^{5}$ (interface de $R$ pour les analyses multidimensionnelles de textes et de questionnaires). O Iramuteq

\footnotetext{
${ }^{5}$ Interface R para análises multidimensionais de textos e questionários.
} 
foi desenvolvido na França por Pierre Ratinaud em 2009 e é um programa em código aberto ancorado no ambiente estatístico do software R e na linguagem Python.

O uso do programa de computador proporcionou o aprimoramento do alto volume de textos gerado a partir de entrevistas e grupos focais ao longo da pesquisa-ação. Seu uso viabilizou a separação e a codificação das informações dos corpora, ajudando na localização dos segmentos textuais, calculando a questão da frequência de palavras e realizando análises multivariadas.

Cada segmento de texto (ST) é composto convencionalmente por cerca de três linhas do documento inserido na base de dados. O conjunto de STs é o próprio corpus de análise. Para este artigo, utilizouse a íntegra dos dados do corpus lexicográfico das transcrições dos grupos focais com os estudantes. Trata-se de análise de grupo, ou seja, que não demonstra as respostas de cada sujeito separadamente.

São tratados como ativos os substantivos, adjetivos e verbos; os verbos auxiliares, como complementares. Foram realizados dois tipos de análises textuais:

1) Lexical básica (ou clássica): útil para identificar a quantidade de palavras, a frequência média e hápax (palavras com frequência igual a um), pesquisar o vocabulário e criar formas reduzidas a partir das raízes lexicais.

2) Análise de similitude ou similaridade: mostra um gráfico que representa a ligação entre as palavras do corpus textual. Tem como função auxiliar na identificação da estrutura da construção do corpus e na percepção da aproximação das palavras utilizadas pelos participantes.

Os grupos focais aconteceram no giro 3 e foram realizados entre pesquisadoras e estudantes, em dois momentos: no fim do primeiro semestre letivo de 2016 e no fim do segundo semestre do mesmo ano. Participaram deles 20 estudantes que estudavam no primeiro ano do ensino médio em 2016, selecionados pelas docentes através do critério de frequência ao projeto. Minayo (2014) considera a técnica de grupos focais uma maneira de obter o ponto de vista dos participantes sem precisar agir de forma diretiva. Parte-se do pressuposto de que o ser humano é capaz de formular suas opiniões e expor suas atitudes no ato da interação com o outro.

Obedecendo um roteiro previamente planejado, foi garantida a oportunidade de fala de todos, controlando o tempo e motivando o aprofundamento das discussões. Foram relatadas impressões partindo de duas questões sugeridas pelas pesquisadoras: 1) Você sente que está prestando mais atenção às suas emoções, pensamentos e ações ou tem agido por impulso? Dê um exemplo. 2) Você sente que está prestando mais atenção e respeitando as emoções das outras pessoas? Dê um exemplo. Os registros foram transcritos pela pesquisadora autora da tese e utilizado como corpus de análise.

\section{ANÁLISES E DISCUSSÕES INTERPRETATIVAS, LEXICOGRÁFICAS E DE SIMILITUDE}

Realizou-se uma análise de similitude que resultou na árvore de coocorrências da Figura 1. Essa árvore apresenta seis troncos, eixos ou conjuntos principais: FALAR (em vermelho); COISA (em verde); FICAR (em amarelo); GENTE (em azul); RAIVA (em lilás); AGIR (em azul claro).

\footnotetext{
${ }^{6}$ Utilizaremos letras maiúsculas para destacar os troncos, eixos principais.
} 
Considerou-se o conjunto FALAR como principal por ter sido a palavra mais citada pelos estudantes. Há uma ligação direta com o verbo ESTAR, que por sua vez leva a outras expressões: bater, estressar, brigar, certo e errado'.

Figura 1 - Análise de similitude a partir das percepções dos estudantes sobre o manejo das emoções

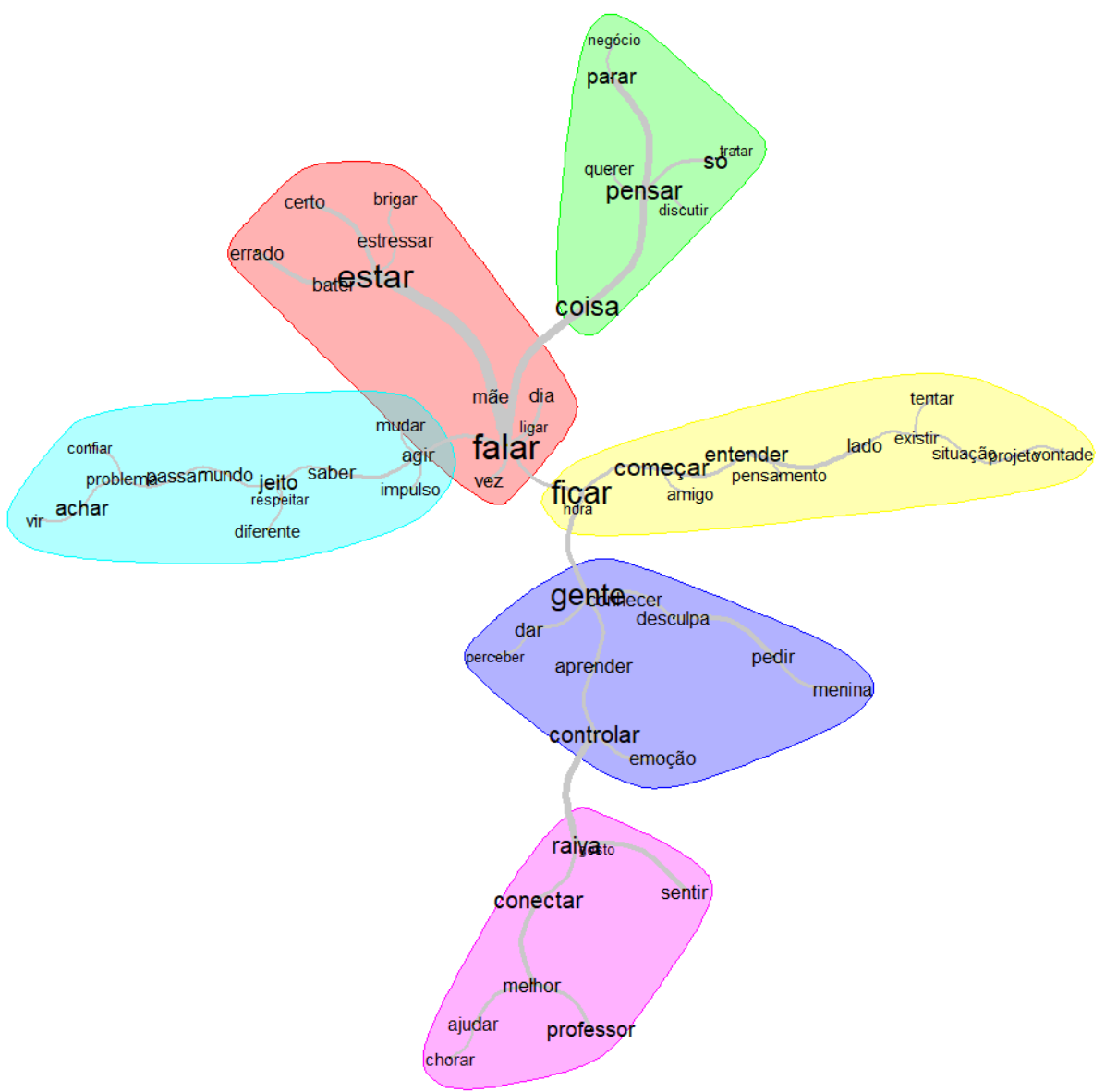

Fonte: Autores.

Qual a relação entre os troncos FALAR e ESTAR e a interpretação das narrativas dos estudantes? Não ter espaço para a fala sobre sentimentos e emoções foi algo bastante presente nos discursos dos sujeitos participantes da pesquisa em vários momentos. Percebe-se que essa falta de oportunidade fazia com que não se sentissem respeitados nos seus sentimentos, emoções e opiniões. Um exemplo disso pode ser observado no relato abaixo, extraído de um grupo focal com estudantes em dezembro de 2016:

Eu passei um tempo sem falar com minha melhor amiga, uma amizade de 9 anos. Aí, a professora falando lá, ela botou uma música... aí a professora pediu pra trazer algo que lembrasse tristeza. Aí, essa minha melhor amiga, ela trouxe uma foto de duas meninas e ela começou a chorar. $O$ [Nome do Projeto] me ajudou a ter o impulso, a coragem de ir lá falar com ela e pedir desculpas. A gente já está bem melhor agora por causa do [Nome do Projeto], a gente chorou demais, mas tudo bem, foi necessário e o [Nome do Projeto] ajudou bastante. (informação verbal, estudante*2016, grifo no original) ${ }^{8}$

Emoções são linguagens (EKMAN, 2011) e sempre têm algo a nos "falar", ou melhor, sinalizar. Ficar sem FALAR com quem se gosta é motivo de tristeza. A professora, ao remeter os estudantes a uma

\footnotetext{
7 Destacaremos em itálico as palavras que surgem nas ramificações.

${ }^{8}$ Nos resultados, utilizamos como referências as codificações do Iramuteq explicitadas anteriormente para assegurar mais sigilo aos participantes.
} 
lembrança de tristeza, fez com que tanto a estudante como sua colega entrassem em contato com a tristeza que as distanciava. Elas precisavam FALAR sobre "ESTAR triste"! Entretanto, foi a amiga que tomou a iniciativa de criar um dispositivo de reaproximação: uma foto de duas meninas.

Do latim emovere, mover para fora (CESAR, 2004), as emoções sinalizam uma dinâmica peculiar presente em camadas mais internas, profundas e sutis do nosso ser que se exteriorizam, modificando/deformando nossos corpos por meio de expressões mais bem percebidas na face e na voz. Elas ligam o nosso mundo interno ao externo (CASSASUS, 2009; 2017; EKMAN, 2011). Atuam como um "termômetro", emitindo sensações de bem-estar e alegria, desconforto e agonia, ou simplesmente neutras. A tristeza das amigas moveu-se para fora! O contato com uma emoção leva ao exercício do autoconhecimento, ou seja, estimula a necessidade de interpretar (pensar) o que se sente para decidir como agir. A foto foi usada como um meio de comunicação sensibilizador, abrindo espaço para a empatia, tendo em vista que ambas reconheceram que sofriam com o afastamento. A comunicação empática constitui uma das habilidades relacionais (WEISSBERG et al., 2015). Ao agir para se reconectar, a amiga tomou uma decisão responsável. Mesmo sem mencionar as competências, o trabalho com as emoções por si só já as promove!

Diretamente relacionadas ao FALAR, foram encontradas três ramificações diretas citadas com maior frequência, representadas em maiúsculo (Figura 1) - COISA, AGIR e FICAR -, e outras indiretas, de frequência inferior, representadas em itálico. Uma COISA, um acontecimento qualquer, pode nos levar a querer parar para pensar. O AGIR pode implicar a mudança de um impulso que precisa encontrar um jeito de saber respeitar. O FICAR com o amigo pode ser uma maneira de tentar começar a entender o seu pensamento para nos sentirmos GENTE. GENTE que pede desculpas e aprende a perceber a controlar a emoção. GENTE que precisa aprender a controlar a RAIVA. Sentir RAIVA, ou qualquer outra emoção, pode ajudar a conectar-se melhor consigo mesmo, às vezes fazendo chorar, e com os demais, incluindo o professor.

A RAIVA foi a primeira emoção trabalhada e por isso foi marcante em todo o processo, o que pode justificar o fato de ser a única emoção citada, ocupando lugar de destaque. Pode-se classificar a raiva como uma emoção central na vida desses estudantes. Mas FALAR sobre a RAIVA por quem se sente RAIVA, no momento da emoção, talvez seja um trabalho ainda mais profundo, pois a RAIVA, nas análises de similitude, está distante do FALAR.

No tronco da RAIVA está o sentir. Muitos de nós podemos agir rotineiramente com raiva sem perceber uma raiva guardada por determinada pessoa. O afastamento das estudantes do relato acima certamente foi provocado pela raiva que sentiram uma da outra. O que a RAIVA desconecta a tristeza pode reconectar! Poder-se-ia dizer que o processo de autoconhecimento, o qual envolve dar lugar dentro de si ao sentir, é nítido no campo da RAIVA, notoriamente incentivado de forma pedagógica pelo Projeto. Sentir as emoções pode estimular a regulação dos impulsos - vide a palavra CONTROLAR, que aparece no tronco azul entre RAIVA e FALAR, conforme os relatos abaixo:

Eu gosto de sentir raiva. Eu não gosto do motivo que me faz sentir raiva, mas eu gosto de ficar com raiva, daquela vontade de quebrar alguma coisa, de bater em alguém. Mas eu não sou assim, não, só que eu consegui controlar mais, eu consigo, como é que eu posso dizer, sentir a raiva, mas não desconto em quem não tem nada a ver. Eu costumava sentir muito isso, sentir uma raiva de alguma pessoa, vinha alguém falar comigo e eu tipo começava a gritar "sai daqui", então eu parei com isso, eu penso mais antes de fazer as coisas. (informação verbal, estudante*2016, grifo no original) 
Às vezes, antes, eu não me policiava pra falar as coisas porque antes, quando eu brigava com uma pessoa, eu brigava pra magoar mesmo e, se fosse pior, eu partia pra briga, mas agora eu tento me controlar e eu evito falar com pessoas que não me dou bem pra não brigar. (informação verbal, estudante*2016, grifo no original)

Observa-se o quanto o gerenciamento da FALA pode contribuir com a autorregulação, o "controle", da RAIVA. Chama-se a atenção para o fato de que as pesquisadoras evitam utilizar o verbo "controlar" para estimular o gerenciamento das emoções, tendo em vista que o entendimento de "controle" pode sugestionar uma repressão às emoções. No Projeto, nota-se que em momento algum houve orientação nesse sentido, e sim um movimento de acolher as emoções (sentir), refletir sobre elas (pensar) e procurar encontrar uma forma respeitosa de agir.

FALAR tem uma ligação direta com AGIR para mudara intensidade de um impulso. A ramificação do AGIR leva a: saber, jeito, respeitar, diferente, mundo, problema, achar, confiar. O percurso para chegar em confiar segue o caminho de saber respeitar o diferente, o jeito e o mundo do outro. Com efeito, no percurso da educação socioemocional, percorrer tal distância entre o autoconhecimento e as decisões responsáveis abarca regular impulsos, saber a melhor forma de falar, mas sobretudo respeitar o que é diferente. Respeito é um valor com o qual precisamos nos comprometer a fim de que seja feita a escolha de orientar-se por ele. Os valores constituem a dimensão espiritual (RÖHR, 2010, 2013), capaz de orientar as ações humanas para fins harmônicos. Röhr (2010), indica que esta dimensão não se confunde com aspectos religiosos e toma a espiritualidade como um sentido existencial de vida que elicia um comprometimento com a coerência entre o pensar, sentir e agir.

As dinâmicas pedagógicas do Projeto oportunizam o FALAR. Inclusive as professoras instituíram um "bastão da fala" para ajudar as turmas a se autogerenciar. Para FALAR é preciso pegar o bastão! Nesses momentos, muitos estudantes externavam seus sentimentos de raiva, tristeza, medo para o grupo. As professoras relataram o respeito e a confiança que os estudantes passaram a ter uns pelos outros. Isso se reflete no seguinte relato:

Eu acho que confiança é um assunto muito delicado, porque geralmente a traição vem de pessoas que você não imagina. $\mathrm{E}$, quando você é traído, você fica assustado, é como se você visse traição em tudo, como se você não acreditasse em nada. E pra você poder passar a confiar em alguém novamente é algo difícil porque assusta, é assustador. E eu tinha problemas pra confiar em algumas pessoas. Eu acho que eu tenho problema pra confiar em todo mundo, só que eu passei a confiar em poucas pessoas e, do mesmo jeito que eu confio nelas, elas confiam em mim. Eu acho que essa vai ser a nossa ligação e eu quero que continue sendo assim. (informação verbal, estudante*2016, grifo no original)

O estabelecimento de uma relação de confiança está no patamar mais elevado das relações interpessoais. Confiar pressupõe cultivar a honestidade, a sinceridade, o profundo respeito pelo outro, portanto depende da vigilância constante da nossa maneira de sentir, pensar e agir.

O terceiro ramo liga o FALAR ao FICAR, termos que expressam um dos objetivos do projeto: falar sobre as emoções para permitir que as relações mantidas na escola sejam cada vez mais saudáveis. Mas, para que isso aconteça, o próprio eixo aponta um caminho interligando as palavras começar, amigo, entender, pensamento, lado, existir, tentar, situação, projeto e vontade.

Eu não conseguia me colocar no lugar das pessoas, eu enxergava só meu lado. Só que, de um tempo pra cá, eu comecei a tentar entender o lado dos outros, porque na história não existe só o meu lado. Existe o lado da outra pessoa e eu me coloco no lugar, me vejo na situação dela. Eu tento ter o mesmo 
pensamento que ela está tendo, entender o que ela está tentando explicar. (informação verbal, estudante*2016, grifo no original)

A empatia é uma habilidade relacional essencial para o aprimoramento da fala e da escuta. Cultivando-a, abre-se espaço para tentar entender o pensamento de um amigo. Observaram-se nesse relato caminhos para um despertar do autoconhecimento e da autogestão emocional. Perceber a importância de incluir a perspectiva do outro, de pensar como ele para compreendê-lo, tem sido um dos grandes achados possíveis de uma pesquisa em HSEV na educação.

O desenvolvimento da percepção da perspectiva do outro leva os estudantes a olhar os docentes de forma mais humana também, e isso os aproxima, como pode-se perceber a seguir:

[...] com as conversas que a gente teve na aula, a gente viu que os professores também têm problemas e começou a entender o lado deles. Ou vamos dizer que alguém sofria bullying, a gente aprendeu que, porque ele sofria bullying com aquilo, ele realmente ficava mal e se estava certo fazer aquilo com ele. (informação verbal, estudante*2016, grifo original)

A compreensão mútua entre docentes e discentes é um processo vital para a melhoria do clima emocional em qualquer ambiente escolar, apontado pelas próprias docentes participantes do Projeto. À medida que pensavam no outro, os alunos também voltavam a refletir sobre si mesmos, pois desse modo "você vê as outras pessoas de um jeito diferente".

0 projeto em si ajudou bastante a relação entre alunos, professores, porque, como ela falou, ele ajudou a gente a conhecer o próximo, a conhecer o lado de cada um, ajudou a compreender melhor as situações. (informação verbal, estudante*2016, grifo original)

O conjunto FICAR leva ao eixo GENTE, que abriga os termos conhecer, desculpa, pedir, menina, dar, perceber, aprender, controlar e emoção. A conexão entre essas expressões leva-nos a inferir que o ato de pedir desculpas, perceber melhor o ponto de vista dos demais, "controlar" a impulsividade das emoções, por exemplo, são exercícios que podem favorecer a humanização, o "aprender a ser GENTE".

Eu tenho um professor que sempre diz que o equilíbrio é a chave de tudo, então muitas vezes eu já cheguei a me desequilibrar com minhas próprias emoções, às vezes de explodir, às vezes de me fechar demais, e com essa atividade eu aprendi que precisa ter um equilíbrio, você tem horas pra ficar mais na sua, você tem horas pra falar mais, e eu acho isso importante, você pode levar isso pra sua vida. (informação verbal, estudante*2016, grifo nosso)

Um Projeto voltado para o desenvolvimento de habilidades socioemocionais extrapola o ambiente escolar, tendo em vista que o despertar para o autoconhecimento, a autogestão, as habilidades relacionais e a tomada de decisão responsável passa a afetar os envolvidos em todas as suas relações interpessoais. Não demora para os sujeitos perceberem que o Projeto não é apenas COISA de escola, mas principalmente para a vida em sociedade!

Eu e minha mãe, a gente é bem diferente e tem algumas coisas que a gente não bate. Antes eu batia de frente com ela, mas agora eu não falo mais nada e fico calada. [...] às vezes a pessoa tá assim toda agitada e você não sabe o que é e você brinca com aquela pessoa e causa mais confusão. Então, eu acho que as duas coisas que eu aprendi é não julgar as pessoas, porque tem muitas pessoas que têm problema que você nem sabe que tinha, e também não provocar raiva no outro porque, do mesmo jeito que é ruim você provocar raiva, é ruim as pessoas provocar 
raiva em você também. É ruim provocar raiva nos outros e, quando você parte pra agressão física, também doí muito, muito mesmo, tanto na pessoa que bateu quanto na pessoa que recebeu, e às vezes essa agressão não fica nem no seu corpo, mas fica na sua mente. (informação verbal, estudante*2016, grifo nosso)

Observou-se com esse rico relato que o(a) estudante tomou uma decisão responsável de não "bater de frente" com sua mãe, e se calar para tentar acalmá-la, contribuindo para o próprio equilíbrio e o da mãe. Esse silenciar-se remete ao acolhimento promovido pela escuta empática, indicando uma abertura para os diversos aspectos de expressão da fala e não apenas a concreta/verbalizada. Essa atitude pode ser entendida como um amadurecimento emocional, que resulta de autoconhecimento e autorregulação da raiva: pensar mais antes de agir. Ressaltou-se ainda o reconhecimento por parte do(a) estudante de que somos um todo multidimensional integrado e que agressões físicas atingem a dimensão mental e, consequentemente, a emocional. Outro sinal importante é a busca pelo não julgamento do outro, tendo em vista que pouco se conhece daquilo que as pessoas estão sentindo ou enfrentando. A empatia é um canal de amorosidade e cuidado com os demais. Na fala a seguir, é possível verificar que o(a) estudante passou a rever a forma como tratava a professora:

Eu e a professora $[\ldots]^{9}$, a gente não se dava bem nem um pouquinho. Só que com o tempo ela foi aplicando o [Nome do Projeto] e eu vi que ela era uma pessoa completamente diferente do que eu pensava que ela era, e não tinha necessidade de eu tratar ela do jeito que eu tratava e dela me tratar do jeito que ela me tratava, porque ela também não me conhecia. Daí a gente foi se conhecendo e eu vi que ela é realmente uma mulher incrível. (informação verbal, estudante*2016, grifo no original)

\section{CONSIDERAÇÕES FINAIS}

Pesquisar as emoções na educação é desafiador para todos os envolvidos, tendo em vista que se faz necessária uma implicação existencial com aquilo que se propõe. Não se trata de conteúdos teóricos apenas como tradicionalmente são transmitidos na escola, mas de conteúdos associados a uma prática de interiorização que requer constante auto-observação, ainda tão incipiente na nossa cultura.

Fazer uso de uma intervenção participativa enriquece e engaja o educador-pesquisador no processo, equiparando seus saberes da prática pedagógica àqueles teórico-filosóficos de cunho acadêmico. Com isso, a parceria se fortalece, desenvolvendo a todos humanamente.

Nesse sentido, infere-se que o Projeto Conecte-se: Sentindo, Pensando e Agindo estimulou o desenvolvimento de competências socioemocionais, promovendo estratégias pedagógicas para a humanização das relações entre docentes e estudantes à medida que foram regulando a força impulsiva das emoções para compreender melhor os outros.

A partir das análises interpretativas, lexicográficas e de similitude, elenca-se que é relevante para o andamento de um processo dessa natureza: manter uma escuta sensível quanto às vivências dos participantes; perceber os docentes como copesquisadores, entendendo que os fundamentos teóricos integrados à experiência prática deles geram conhecimento e que se devem respeitar as singularidades de cada docente. Consequentemente, o desenvolvimento de habilidades como autoconhecimento e autogestão estimulou a compreensão mútua, promovendo a empatia entre os

\footnotetext{
${ }^{9} \mathrm{O}$ nome da professora foi retirado para garantir o sigilo dos participantes.
} 
participantes (docentes-discentes, discentes entre si) e contribuiu para a regulação da impulsividade, proporcionando relações mais humanizadas no ambiente escolar em foco.

A continuidade de pesquisas nesse campo é essencial para que as próximas gerações possam partir de um conhecimento consolidado tanto em seus aspectos formativos como nos práticos, a partir de resultados de iniciativas implementadas no chão das escolas.

\section{REFERÊNCIAS}

ARANTES, Mariana Marques. Educação Emocional Integral: análise de uma proposta formativacontinuada participante de estudantes e professores em uma escola. 2019. 275 f. Tese (Doutorado) - Curso de Educação, Centro de Educação, Universidade Federal de Pernambuco, Recife, 2019.

ARROYO, M. O direito a tempos-espaços de um justo e digno viver. In: MOLL, J. et al. Caminhos da Educação Integral no Brasil: direito a outros tempos e espaços educativos. Porto Alegre: Penso, 2012.

BARBIER, R. A pesquisa-ação. Brasília: Liber Libro, 2007.

Brasil, Ministério da Educação. Secretaria de Educação Básica. Educação Integral/Educação Integrada $\mathrm{e}(\mathrm{m})$ tempo integral: concepções e práticas na educação brasileira- Mapeamento das experiências de jornada escolar ampliada no Brasil: estudo qualitativo. - Brasília, 256 p.:il. - (Série Mais Educação), 2015.

CAMARGO, B. V.; JUSTO, A. M. Iramuteq: um software gratuito para análise de dados textuais. Temas psicol., Ribeirão Preto, v. 21, n. 2, p. 513-518, dez. 2013. DOI http://dx.doi.org/10.9788/TP2013.2-16. Disponível em: http://pepsic.bvsalud.org/scielo.php?script=sci_arttext\&pid=S1413389X2013000200016\&lng=pt\&nrm=iso. Acesso em: 26 mar. 2020.

CASASSUS, J. Fundamentos da Educação Emocional. 1. ed. Brasília: Liber Editora, 2009. 252 p. CASSASUS, J. Una introducción a la Educación Emocional. Revista Latinoamericana de Políticas y Administración de la Educación, v. 4, n. 7, p. 121-130, Dic. 2017-Jun. 2018.

CESAR, B. O Livro das emoções: reflexões inspiradas na psicologia do budismo tibetano. São Paulo: Gaia, 2004.

CAVALIERE, A. M. Escola pública de tempo integral no Brasil: Filantropia ou política de Estado? Educação \& Sociedade, 2014.

CUNHA, D. P. da. Fundamentos paradigmáticos da formação humana: contribuições dos paradigmas transpessoal, intercultural e da espiritualidade para a educação no Brasil e na França. 2017. 416 f. Tese (Doutorado em Educação) - Universidade Federal de Pernambuco; Université de Lyon, Recife; Lyon, 2017.

DELORS, J. Educação: um tesouro a descobrir. Brasília: UNESCO, 1996.

EKMAN, P. A linguagem das emoções: Revolucione sua comunicação e seus relacionamentos reconhecendo todas as expressões das pessoas ao redor. Tradução: Carlos Szlak. São Paulo: Lua de Papel, 2011. 
MOLL, J. et al. Caminhos da Educação Integral no Brasil: direito a outros tempos e espaços educativos. Porto Alegre: Penso, 2012.

FUNDACIÓN BOTÍN. Educación Emocional y Social. Análisis Internacional. Informe Fundación Botín, 2011. Disponível em: https://www.fundacionbotin.org/educacion-contenidos/educacionemocional-y-social- analisis-internacional.html. Acesso em: 19 ago. 2019.

FUNDACIÓN BOTÍN. Educación Emocional y Social. Análisis Internacional. Informe Fundación Botín, 2013. Disponível em: https://www.fundacionbotin.org/educacion-contenidos/educacionemocional-y-social- analisis-internacional.html. Acesso em: 19 ago. 2019.

FUNDACIÓN BOTÍN. Educación Emocional y Social. Análisis Internacional. Informe Fundación Botín, 2015. Disponível em: https://www.fundacionbotin.org/educacion-contenidos/educacionemocional-y-social- analisis-internacional.html. Acesso em: 19 ago. 2019.

FUNDACIÓN MARCELINO BOTÍN. Educación Emocional y Social. Análisis Internacional. Informe Fundación Marcelino Botín, 2008. Disponível em: https://www.fundacionbotin.org/educacioncontenidos/educacion-emocional-y-social- analisis-internacional.html. Acesso em: 19 ago. 2019.

GOLEMAN, D. Inteligência Emocional: a teoria revolucionária que define o que é ser inteligente. Tradução: Marcos Santarrita. Rio de Janeiro: Objetiva, 2007.

MINAYO, M. C. de S. O desafio do conhecimento: pesquisa qualitativa em saúde. 14. ed. São Paulo: Hucitec, 2014.

POLICARPO JUNIOR, J. et al. O Pensar, o Sentir o Agir: Sentidos da Formação Humana. Recife: Instituto de Formação Humana, 2011. Livro eletrônico.

RÖHR, F. et al. (Orgs.). Diálogos em educação e espiritualidade. Recife: Universitária UFPE, 2010. 410 p.

RÖHR, F. Educação e espiritualidade: contribuições para uma compreensão multidimensional da realidade, do homem e da educação. Campinas: Mercado das Letras, 2013.

SALOVEY, P.; MAYER, J. D. Emotional Intelligence. In: SALOVEY, P.; BRACKETT, M.; MAYER, J. Emotional Intelligence: key readings on the Mayer and Salovey Model. New York: Dude Publishing, 2004.

SILVA, M. M. da. A formação de competências socioemocionais como estratégia para captura da subjetividade da classe trabalhadora. Tese (Doutorado em Educação Escolar) Universidade Estadual Paulista "Júlio de Mesquita Filho", Araraquara, 2018.

SILVA, K. N. P.; SILVA, J. A. de A. Política de Avaliação e Programa de Educação Integral no Ensino Médio da Rede Estadual de Pernambuco: os limites da centralidade da avaliação nas políticas educacionais. Ponta Grossa: Práxis Educativa, Ponta Grossa, p. 736-756, v. 11, n. 3, set./dez. 2016. Disponível em: http://www.revistas2.uepg.br/index.php/praxiseducativa. Acesso em: 20 set. 2018.

WEISSBERG, R. et al. Social and Emotional Learning: past, present and future. In: DURLAK, J. A. et al. Handbook of Social and Emotional Learning. New York: The Guilford Press, 2015.

Submissão: 10/09/2020

Aceito: 19/09/2020 